\title{
Did the FED React to Asset Price Bubbles?
}

Marc-Andre Luik*

Helmut-Schmidt University, Hamburg
Dennis Wesselbaum†

University of Otago and EABCN

Address for correspondence:

Dennis Wesselbaum

Department of Economics

University of Otago

PO Box 56

Dunedin

NEW ZEALAND

Email: dennis.wesselbaum@otago.ac.nz

Telephone: 6434798643 


\title{
Did the FED React to Asset Price Bubbles?
}

\author{
Marc-Andre Luik* \\ Helmut-Schmidt University, Hamburg
}

\author{
Dennis Wesselbaum ${ }^{\dagger}$ \\ University of Otago and EABCN
}

February 2, 2016

\begin{abstract}
This paper investigates whether the U. S. Federal Reserve responds to asset price bubbles or not. We estimate a DSGE model featuring a financial accelerator and a process for asset price bubbles. We find evidence for a fairly strong reaction to bubbles. However, a counterfactual analysis shows that output is lower if the central banks reacts to the asset price bubble. Finally, we estimate an asymmetric version in which the central bank only reacts to positive price deviations. This version generates the best statistical fit. Including the bubble reduces the negative effects of the recent financial crisis but the symmetric response would have generated an earlier and stronger recovery.
\end{abstract}

Keywords: Bayesian Methods, Bubbles, Monetary Policy.

JEL codes: C11, E32, E44, E62.

${ }^{*}$ Helmut-Schmidt University, Chair of Political Economy and Empirical Economics, Holstenhofweg 85, 22043 Hamburg, Germany. Tel: +49-040-6541-3809. Email: luikma@hsu-hh.de.

${ }^{\dagger}$ University of Otago, Department of Economics. P.O. Box 56, Dunedin 9054, New Zealand. Email: dennis.wesselbaum@otago.ac.nz. 


\section{Introduction}

The housing market bubble in the United States and the following Great Recession made one thing crystal clear: shocks emerging in the financial sector of the economy can generate large, adverse effects on the real economy. Along this line, central banks around the world were heavily criticized for not, or not sufficiently strongly, reacting to the turbulence in the financial sector. For academics and policy makers the question was recuscitated whether central banks should respond to asset price bubbles, a discussion formerly known as the "lean" versus "clean" debate.

While "leaning" against a potentially developing bubble entails preemptive action in order to decrease the bubble's pace, "cleaning" sticks with the usual stabilization objectives throughout the boom and instead focuses on extractive monetary policy after the bust (Mishkin, 2011). However, given the potential consequences of asset price misalignment, it is not a question of whether or not but how much, relative to the classic stabilization objectives, we should respond (Mishkin, 2011).

Early proponents of "lean" policy, like Cecchetti et al. (2000), state that public "leaning", specifically reacting to asset prices misalignment, could decrease the likelihood of future asset price bubbles and thereby even decrease output volatility, e.g. via limiting the potential moral hazard of "cleaning up" (see, e.g. Issing, 2011; Farhi and Tirole, 2012). Arguments in favor of "cleaning" are mainly operational (Mishkin, 2011). First, bubbles are hard to detect and proponents of this view doubt that a central bank can have an informational advantage against the market. Second, normal instruments are unlikely to work in abnormal conditions. Especially, monetary policy interest rate rules are too blunt to target asset-specific bubbles and may lead to a severe bust. Most importantly, prior to the Great Recession, proponents of the "clean" policy believed that traditional monetary policy can maintain the costs of a bursting bubble at a manageable level. In retrospective the Great Recession delivered some painful insights into the discussion and prove certain arguments wrong. The costs of the Great Recession were far higher than any manageable level. Moreover, output and price stability do not warrant financial stability (Issing, 2011). The recent events also necessitate a differentiation of bubble types. While "irrational exuberance" poses limited systematic risk to financial stability, "credit-driven bubbles" have shown to be a larger thread to the system (White, 2009; Mishkin, 2011).

Bernanke and Gertler $(1999,2001)$ issue the theoretical foundation of the "clean" argument. Based on a series of simulations of the financial accelerator framework by Bernanke et al. (1999), including an exogenous asset price bubble, they conclude that flexible but aggressive inflation targeting suffices to obtain price and financial stability. Extending the Taylor rule by stock market returns, does result in no sizable gain. ${ }^{1}$ Cecchetti et al. $(2000,2002)$ use the same setup of Bernanke and Gertler $(1999,2001)$ and show that a reaction to stock prices reduces overall volatility. ${ }^{2}$ In addition to the setup of Bernanke and Gertler $(1999,2001)$ their optimal monetary policy also targets output. ${ }^{3}$

More recent works focus on the reaction to fundamental stock market movements. Using welfare metrics, Faia and Monacelli (2007) do not report any welfare improvement by responding to

\footnotetext{
${ }^{1}$ Other works inferring negligible gains from "leaning" include Gilchrist and Leahy (2002) and Tetlow (2005).

${ }^{2}$ Other works stressing the benefits of "leaning" monetary policy role include Bordo and Jeanne (2002), Filardo (2001, 2004), and Dupor (2001, 2005). Bean (2004) and Detken and Smets (2004) point out that a reaction to asset price might be beneficial but is dependent on the information structure of the economy and the targeted asset bubble symptom.

${ }^{3}$ It is worth stressing, that Cecchetti et al. (2002) do not advocate the strict inclusion of asset prices into the monetary policy rule or objective function but to react systematically to asset price misalignment. Moreover, they point out, that "leaning" against a bubble does not include "picking" it, as history has shown severe outcomes of the latter.
} 
the stock market. Gilchrist and Saito (2008) model asset price swings through changes in trend growth and assume the agents to learn about them over time. The gap, being a product of financial imperfections, offers a motivation to allow a reaction to asset price gaps (potential asset prices vs. observed asset prices). However, the success of this policy depends on the available information in the economy. While limited information reduces the gain of this policy, ignoring potential asset price changes leads to an inferior outcome. Carlstrom and Fuerst (2007) take a different angle of the discussion and point out that trying to avoid bubbles can "inadvertently" introduce equilibrium indeterminacy and non-fundamental movements in asset prices and real activity. Ravn (2014) presents a DSGE model with asymmetric monetary policy responses to capital market drops. Limiting the reaction to stock market drops, the economy experiences an asymmetric business cycle with amplified booms in output and inflation and dampened recessions. Furthermore, introducing asymmetric monetary policy leads to an anticipation boom in asset prices. However, calibrating monetary policy based on empirical evidence on asymmetrical responses indicates only minor macroeconomic effects.

While there are normative arguments for both sides of the debate, there is also empirical evidence on this issue. Rigobon and Sack (2004) show that monetary policy responds to changes in stock prices and thereby affects the macroeconomy. Comparing inflation regimes, Dupor and Conley (2004) detect stock market responses during low inflation periods. Fuhrer and Tootell (2008) do not find evidence for a FOMC response to the stock market. Bjornland and Leitemo (2009) estimate a vector autoregressive model to tackle the interdependency between monetary policy and real stock prices and find effects in both directions. Ravn (2012) and Hoffmann (2013) deliver evidence in favor of asymmetric monetary policy reaction. They show that the Fed reacts especially to drops in the stock market. Hall (2011) adds stock price deflation to a Taylor rule and estimates a negative estimation coefficient with better model fit. ${ }^{4}$

In this paper, we investigate whether the U. S. Federal Reserve (FED, for short) responds to asset price bubbles or not. In contrast to the related literature, we focus on the reaction to an estimated bubble process. We do so by estimating a medium-size DSGE model of the U. S. economy. Our model features a financial accelerator model as in Bernanke et al. (1999) (BGG, for short) and fiscal policy (government spending and taxes) follows fiscal feedback rules. Our model further allows to estimate a non-fundamental shock which we interpret as a bubble. This bubble, technically, is a shock to the capital no-arbitrage equation. Identification is achieved by exploiting the wedge between the observed Tobin's q and the one endogenously created by our model. The advantage of this approach is that it allows us to interpret this bubble as being created by any factor that would create a wedge between the fundamental value of capital and the observed price. ${ }^{5}$ In our framework the monetary authority is therefore able to identify the bubble. In order to detect a response to bubbles we incorporate and estimate different monetary policy formulations in our model framework and compare the respective goodness of fit. We find that the inclusion of a reaction to bubbles improves the model fit to the data. Moreover, the estimated reaction coefficient to the non-fundamental component is close to unity. Together with the strong inflation targeting this result indicates an active response to bubbles.

A counterfactual analysis, comparing a model with a reaction to the asset price bubble in the Taylor rule vs. a model without a reaction, shows that the output level is lower if the central banks

\footnotetext{
${ }^{4}$ That monetary policy can also have effects on the bubble build-up has been indicated by Bekaert et al. (2013). They point out that lax monetary policy decreases risk aversion and to a lower extent uncertainty. This potential feedback channel is not subject of this analysis but remains an important future research direction.

${ }^{5}$ Other studies of bubbles in DSGE models include Christiano et al. (2010), Miao et al. (2012), Wang and Wen (2012), Ikeda (2013), and Liu et al. (2013).
} 
reacts to the asset price bubble.

Finally, we estimate an asymmetric version and find that it only marginally increases the fit to the data. It does generate a better fit compared to the symmetric rule before 1992 but a worse fit afterwards. We can draw the conclusion that the FED does react to movements in asset prices but a counterfactual analysis shows that this leads to a lower output level. Including the bubble reduces the negative effects of the recent financial crisis but the symmetric response would have generated an earlier and stronger recovery. However, we highlight that our analysis does not take into account that the FED's policy could have reduced the probability of bubbles.

\section{Model Derivation}

We develop a New Keynesian model with financial frictions - based upon the work by Bernanke et al. (1999) - and allow for non-fundamental deviations (a.k.a. a bubble) in asset prices - as in Ratto et al. (2010), In't Veld et al. (2011), and Luik and Wesselbaum (2014). Our economy is populated by five agents: households, entrepreneurs, retailers, a central bank, and a fiscal authority. Time is discrete and the length of a period is a quarter.

\subsection{Households}

We assume that our economy is populated by a continuum of infinitively-lived identical households. Each of which consists of a continuum of family members of measure one. Households preferences are given by

$$
\mathbb{E}_{0}\left\{\sum_{t=0}^{\infty} \beta^{t}\left[\ln C_{t}-\vartheta \ln \frac{M_{t}}{P_{t}}+\varrho \ln \left(1-H_{t}\right)\right]\right\},
$$

where consumption, real money holdings, and hours are denoted by $C_{t}, \frac{M_{t}}{P_{t}}$, and $H_{t}$. Further, labor supply elasticity is given by $\varrho>0$ and $\vartheta>0$. Moreover, $\mathbb{E}_{t}$ denotes the expectation conditional on the information available at $t=0$ and $\beta \in(0,1)$ is the household's discount factor.

The representative household faces the budget constraint

$$
C_{t} \leq W_{t} H_{t}-T_{t}+\Pi_{t}+R_{t} D_{t}-D_{t+1}+\frac{M_{t+1}-M_{t}}{P_{t}}
$$

where $T_{t}$ are lump sum taxes and $D_{t}$ are deposits held at intermediaries. In equilibrium, household deposits at intermediaries, $D_{t}$, equal total loanable funds supplied to entrepreneurs, $B_{t}$. Households receive dividends, $\Pi_{t}$, and earn a wage, $W_{t}$.

The solution to the problem maximizing (1) subject to (2) gives the following FOC's

$$
\begin{aligned}
C_{t}^{-1} & =\beta \mathbb{E}_{t} C_{t+1}^{-1} R_{t+1}, \\
\frac{W_{t}}{C_{t}} & =\varrho \frac{1}{1-H_{t}}, \\
\frac{M_{t}}{P_{t}} & =\vartheta C_{t}\left(\frac{R_{t+1}^{n}-1}{R_{t+1}^{n}}\right)^{-1},
\end{aligned}
$$

where $R_{t+1}^{n}$ is the net nominal interest, $i_{t+1}=R_{t+1} \frac{P_{t+1}}{P_{t}}-1$.

The first condition (3) is the standard Euler equation for the path of consumption. The second equation (4) is the labor supply schedule and the last equation (5) relates real money holdings to consumption and the net nominal interest rate. 


\section{$2.2 \quad$ Firms}

Our economy is populated by a continuum of identical firms. They operate under monopolistic competition and set prices à la Calvo (1983). Entrepreneurs produce wholesale goods under perfect competition, while retail sector firms buy the wholesale good, costlessly differentiate them, and sell those final goods to the households.

\subsubsection{Retailers}

Retail firms use a Dixit-Stiglitz technology to produce final output, $Y_{t}^{f}$,

$$
Y_{t}^{f}=\left[\int_{0}^{1} Y_{t}(z)^{\frac{\epsilon-1}{\epsilon}} \mathbf{d} z\right]^{\frac{\epsilon}{\epsilon-1}} .
$$

Here, $Y_{t}(z)$ denotes the quantity of output sold by retail firm $z$ and $\epsilon>1$.

From the optimization program of the representative firm, the overall demand addressed to the producer $z$ is

$$
Y_{t}(z)=\left(\frac{P_{t}(z)}{P_{t}}\right)^{-\varepsilon} Y_{t}^{f}
$$

where the price index is defined by

$$
P_{t}(z)=\left[\int_{0}^{1} P_{t}(z)^{1-\epsilon} \mathbf{d} z\right]^{\frac{1}{1-\varepsilon}} .
$$

The retailer chooses the optimal price $P_{t}(z)$ facing a downward-sloping demand curve and is only able to set the optimal price in a given period with probability $1-\theta>0$.

Let $Y_{t}^{*}$ be the resulting demand of the optimal price $P_{t}^{*}$ set at $t$ by firms who are able to change prices by maximizing the expected discounted stream of profits

$$
\sum_{t=0}^{\infty} \theta^{t} \mathbb{E}_{t-1}\left[\Lambda_{t} \frac{P_{t}^{*}-P_{t}^{w}}{P_{t}} Y_{t}^{*}(z)\right]
$$

in which $\Lambda_{t}=\beta \frac{C_{t}}{C_{t+1}}$ denotes the stochastic discount factor and the wholesale price is $P_{t}^{w}=P_{t} / X_{t}$.

The first-order condition w.r.t. the optimal price is

$$
\sum_{t=0}^{\infty} \theta^{t} \mathbb{E}_{t-1}\left[\Lambda_{t}\left(\frac{P_{t}^{*}}{P_{t}}\right)^{-\varepsilon} Y_{t}^{*}(z)\left(P_{t}^{*}-\left(\frac{\varepsilon}{\varepsilon-1}\right) P_{t}^{w}\right)\right]=0 .
$$

Hence, the optimizing retail firm sets its price such that discounted marginal revenues equal discounted marginal costs. Finally, the aggregate price follows

$$
P_{t}=\left[\theta P_{t-1}^{1-\varepsilon}+(1-\theta)\left(P_{t}^{*}\right)^{1-\varepsilon}\right]^{\frac{1}{1-\varepsilon}} .
$$

\subsubsection{Entrepreneurs}

Entrepreneurs produce wholesale goods using a constant returns to scale production technology. They use capital, $K_{t}$, and labor services, $L_{t}$, in the Cobb-Douglas production function

$$
Y_{t}=Z_{t} K_{t}^{\alpha} L_{t}^{1-\alpha},
$$


where $\alpha>0$ and $Z_{t}$ is a Hicks-neutral technology shock. The shock follows a first-order autoregressive process

$$
\ln Z_{t}=\rho_{Z} \ln Z_{t-1}+e_{Z, t}, e_{Z, t} \sim \mathcal{N}\left(0, \sigma_{Z}\right),
$$

where $0<\rho_{Z}<1$ determines the degree of autocorrelation and its innovation is i.i.d. over time and normally distributed.

Further, we assume that households own the capital stock which accumulates according to

$$
K_{t+1}=u_{t}^{S} \Phi\left(\frac{I_{t}}{K_{t}}\right) K_{t}+(1-\delta) K_{t},
$$

where $I_{t}$ is investment and $\Phi(\cdot)$ captures capital adjustment costs (see Christiano et al. (2005)), in order to allow for a variable price of capital. ${ }^{6}$ Furthermore, $\delta>0$ denotes the exogenous rate of depreciation. The shock to marginal efficiency of investment is denoted by $u_{t}^{S}$ and follows an $\operatorname{AR}(1)$

$$
\ln u_{t}^{S}=\rho_{S} \ln u_{t-1}^{S}+e_{S, t}, e_{S, t} \sim \mathcal{N}\left(0, \sigma_{S}\right)
$$

where $0<\rho_{S}<1$ determines the degree of autocorrelation and its innovation is i.i.d. over time and normally distributed.

The price of a unit of capital in terms of the numeraire good, $Q_{t}$, is given by

$$
Q_{t}=\left[u_{t}^{S} \Phi^{\prime}\left(\frac{I_{t}}{K_{t}}\right)\right]^{-1}
$$

The bubble process follows the definition given in Ratto et al. (2010) and In't Veld et al. (2011): We define the capital market price as

$$
\tilde{Q}_{t}=Q_{t}+\psi_{t}
$$

where $\psi_{t}$ follows the near rational bubble process

$$
\psi_{t+1}=\left\{\begin{array}{c}
\left(\frac{a}{p}\right) \psi_{t}\left(1+R_{t}\right)+u_{t}^{B}, \text { with probability } p \\
0, \text { with probability } 1-p
\end{array},\right.
$$

such that the expected value is given by

$$
\mathbb{E}_{t}\left\{\psi_{t+1}\right\}=a \psi_{t}\left(1+R_{t}\right)
$$

where we impose $a<\frac{1}{1+R}$ in order to allow for a stationary non-fundamental shock in the model.

The non-fundamental shock, $u_{t}^{B}$, in eq. (18) follows a first-order autoregressive process

$$
\ln u_{t}^{B}=\rho_{B} \ln u_{t-1}^{B}+e_{B, t}, e_{B, t} \sim \mathcal{N}\left(0, \sigma_{B}\right),
$$

where $0<\rho_{B}<1$ determines the degree of autocorrelation and its innovation is i.i.d. over time and normally distributed.

At the end of each period $t$, the entrepreneurs acquire physical capital which is used in period $t+1$ to produce wholesale output. They are financed by entrepreneurs net worth, $N_{t+1}$, and borrowing from financial intermediaries, $B_{t+1}=\tilde{Q}_{t} K_{t+1}-N_{t+1}$. The financial intermediary uses

\footnotetext{
${ }^{6}$ The function satisfies $\Phi(\cdot)=0, \Phi^{\prime}(\cdot)=0$, and $\Phi^{\prime \prime}(\cdot)>0$.
} 
households savings and faces an opportunity cost between periods which is equal to the riskless gross rate of return, $R_{t+1} \cdot{ }^{7}$

Due to the costly state verification approach by Townsend (1979), external finance is more expensive than internal funds. In this problem, the lender has to pay a fixed auditing cost in order to observe the borrower's individually realized return while the entrepreneur observes it costlessly. After the realization of the project outcome, the entrepreneur decides whether to repay the loan or default. In case of default, the intermediary will audit the loan and receives the project outcome less monitoring costs.

Entrepreneurs sell wholesale goods to retailers at a perfectly competitive price. Then, there exists a gross mark-up of retail goods over wholesale goods given by $X_{t}$. Given the Cobb-Douglas technology, it follows that the factor price of capital in $t+1$ is $\frac{1}{X_{t}} \frac{\alpha Y_{t+1}}{K_{t+1}}$. This implies a gross return of holding a unit of capital from period $t$ to $t+1$ of

$$
\mathbb{E}_{t}\left[R_{t+1}^{k}\right]=\mathbb{E}_{t}\left[\frac{\frac{1}{X_{t}} \frac{\alpha Y_{t+1}}{K_{t+1}}+(1-\delta) \tilde{Q}_{t+1}}{\tilde{Q}_{t}}\right],
$$

where $R_{t+1}^{k}$ is the interest rate on external funds. Further, eq. (21) is the entrepreneur's demand schedule for capital. On the other hand, the supply curve for investment finance is

$$
\mathbb{E}_{t}\left[R_{t+1}^{k}\right]=\mathbb{E}_{t}\left[s\left(\frac{N_{t+1}}{\tilde{Q}_{t} K_{t+1}}\right) R_{t+1}\right] .
$$

The gross external finance premium, i.e. the ratio of external and internal finance, is given by the concave function $s(\cdot)$, where $s(1)=1$ and $s^{\prime}(\cdot)>0$.

Entrepreneurs inelastically supply labor services and we assume that entrepreneurial labor is distributed on the unit interval. Therefore, total labor is a composition of household's labor supply, $H_{t}$, and entrepreneurial labor supply, $H_{t}^{e}$, such that

$$
L_{t}=H_{t}^{\xi}\left(H_{t}^{e}\right)^{1-\xi},
$$

where $\xi>0$. Entrepreneurial net worth at the end of period $t$ consists of two parts, namely entrepreneurial equity, $V_{t}$, and the entrepreneurial wage earned for labor services, $W_{t}^{e}$. Then, net worth is given by

$$
N_{t+1}=\gamma V_{t}+W_{t}^{e}
$$

where

$$
V_{t}=R_{t}^{k} \tilde{Q}_{t-1} K_{t}-\left[R_{t}+\frac{\mu \int_{0}^{\varpi_{t}} \omega R_{t}^{k} \tilde{Q}_{t-1} K_{t} \mathbf{d} F(\omega)}{\tilde{Q}_{t-1} K_{t}-N_{t-1}}\right]\left(\tilde{Q}_{t-1} K_{t}-N_{t-1}\right),
$$

and $\gamma>0$ is the probability that an entrepreneur survives until the next period. This is a key assumption as it results in the necessity for firms to use external funds, as they will never acquire enough net worth to fully finance the new capital acquisitions.

Those entrepreneurs, namely $1-\gamma$, who do not survive consume the residual equity $C_{t}^{e}=$ $(1-\gamma) V_{t}$. Furthermore, eq. (25) states that earnings from running business in this period become next period's net worth. To be precise, it states that the earnings from holding equity from $t-1$ to

\footnotetext{
${ }^{7}$ Risk-neutral entrepreneurs and risk-averse households imply that the loan contract between the financial intermediary and the entrepreneur absorbs the entire aggregate risk. Hence, the intermediary's portfolio will be perfectly safe and the riskless rate is the relevant opportunity cost.
} 
$t$ less repayments of borrowings will become tomorrow's net worth. The external finance premium is given by

$$
\frac{\mu \int_{0}^{\varpi t} \omega R_{t}^{k} \tilde{Q}_{t-1} K_{t} \mathbf{d} F(\omega)}{\tilde{Q}_{t-1} K_{t}-N_{t-1}}
$$

which is the ratio of default costs to the quantity borrowed. Here, $\omega$ denotes an i.i.d. disturbance to the entrepreneur's return, with $F(\omega)$ being a continuously and twice-differentiable c.d.f, with positive support. Further, $\mu \omega R_{t}^{k} Q_{t-1} K_{t}$ is the monitoring cost, as a share, $\mu>0$, of the gross capital payoff. is

Finally, the missing necessary first-order condition to the entrepreneurs maximization problem

$$
(1-\alpha) \xi \frac{Y_{t}}{H_{t}}=X_{t} W_{t},
$$

which equals the marginal product of labor with the wage.

\subsection{Fiscal and Monetary Authority}

Our fiscal authority has two instruments: bonds, $\Xi_{t}$, and government spending, $G_{t}$. The budget constraint is given by

$$
\Xi_{t}=G_{t}-R_{t-1} \Xi_{t-1}
$$

Following Leeper (1991) and Forni et al. (2009), we assume a debt-based government spending rule that pins down government expenditures

$$
\hat{G}_{t}=-\gamma_{\Xi} \hat{\Xi}_{t}-\gamma_{Y} \hat{Y}_{t}+u_{t}^{G}
$$

where $\gamma_{Y} \geq 0$ accounts for the business cycle stabilization goal of our government and $\gamma_{\Xi} \geq 0$ captures the aim to stabilize debt.

The fiscal policy shock, which can be interpreted as discretionary fiscal policy, follows a standard first-order autoregressive process,

$$
\ln u_{t}^{G}=\rho_{G} \ln u_{t-1}^{G}+e_{G, t}, e_{G, t} \sim \mathcal{N}\left(0, \sigma_{G}\right),
$$

where $0<\rho_{G}<1$ determine the degree of autocorrelation and the innovations are i.i.d. over time and normally distributed.

Monetary policy in our model uses a standard Taylor-type interest rate rule with smoothing

$$
R_{t}=\phi R_{t-1}+(1-\phi)\left[\psi_{y} Y_{t}+\psi_{\pi} \pi_{t}\right]+u_{t}^{R},
$$

where the weight on the lagged interest rate is $\phi>0$ and $\psi_{y}, \psi_{\pi}>0$. Furthermore,

$$
\ln u_{t}^{R}=\rho_{R} \ln \left(u_{t-1}^{R}\right)+e_{R, t}, e_{R, t} \sim \mathcal{N}\left(0, \sigma_{R}\right),
$$

is an exogenous disturbance to the interest rate. Its autocorrelation is driven by $0<\rho_{R}<1$ and its innovation is i.i.d. over time and normally distributed. 


\subsection{Equilibrium}

In the symmetric equilibrium, all markets clear and a feasible allocation satisfies

$$
Y_{t}=C_{t}+I_{t}+G_{t}+\mu \int_{0}^{\varpi_{t}} \omega R_{t}^{k} \tilde{Q}_{t-1} K_{t} \mathbf{d} F(\omega)
$$

For given initial conditions and the stochastic process $\left\{Z_{t}, u_{t}^{B}, u_{t}^{G}, u_{t}^{R}, u_{t}^{S}\right\}_{t=0}^{\infty}$, a determined equilibrium is a state-contingent sequence of $\left\{C_{t}, I_{t}, K_{t}, Q_{t}, R_{t}, R_{t}^{k}, Y_{t}, L_{t}, W_{t}, G_{t}, \pi_{t}, N_{t}, C_{t}^{e}, X_{t}\right\}_{t=0}^{\infty}$ satisfying the optimality and market clearing conditions. Then, the set of equations describing the rational expectation equilibrium are log-linearized around the non-stochastic steady state.

\section{Estimation}

\subsection{Methodology and Data}

We apply the following measurement equation to link the model's variables to our time series

$$
y_{t}=\left[\begin{array}{c}
d Y_{t} \\
d I N V_{t} \\
r_{t} \\
d \tilde{Q}_{t} \\
\log \left(N_{t}\right)
\end{array}\right]=\left[\begin{array}{c}
\bar{\gamma} \\
\bar{\gamma} \\
\bar{\gamma} \\
\bar{\gamma} \\
\bar{l}
\end{array}\right]+\left[\begin{array}{c}
Y_{t}-Y_{t-1} \\
I_{t}-I_{t-1} \\
r_{t} \\
\tilde{Q}_{t}-\tilde{Q}_{t-1} \\
N_{t}
\end{array}\right],
$$

where $\log$ denotes the logarithmic difference and a first differenced series is denoted by $d$. Furthermore, $\bar{\gamma}$ denotes the quarterly growth rate of GDP, $\bar{l}$ denotes the growth rate of labor, and $\bar{r}$ denotes steady state nominal interest rate.

How do we identify the bubble process? Consider the bubble process eq. (18): First, notice that in eq. (17) we observe $\tilde{Q}_{t}$, while $Q_{t}$ is generated by the model. Hence, $\psi_{t}$ can be considered to be the "residual" between observed Tobin's q and the calculated Tobin's q from our model. Once the bubble shock is identified, we can identify the parameters in the assumed formation process (eq. (19) and eq. (20), as two equations for two parameters allow for independent identification.

Time series span the period from 1960:Q1 to 2012:Q4 (208 observations). For the time series log difference of real GDP, real investment, and the log difference of the GDP deflator, we use the time series provided by Smets and Wouters (2007) updated until the last observation. Furthermore, government debt is taken from Bureau of Economic Analysis' NIPA tables.

Further, in order to calculate the time series for Tobin's q, we use data provided by the Federal Reserve Board in its "Flow of Funds Accounts of the United States" (Z.1, B.102). Tobin's q is calculated from the equation

$$
\tilde{Q}_{t}=\frac{\text { Market value of Debt and Equities }- \text { Net Liquid Assets }- \text { Land Value }}{\text { Replacement Costs }}
$$

where the market value of debt is the sum of municipal securities (line 24), corporate bonds (line 25 ), and mortgages (line 28), while the market value of equities is taken from line 35 . Net liquid assets are calculated as total financial assets (line 6) subtracted by the sum of total liabilities (line 21), municipal securities (line 24), corporate bonds (line 25), and mortgages (line 28). The value of land is then derived by subtracting the replacement cost of residential and nonresidential structures ( line 33 and 34) from the market value of real estate (line 3). Finally, the replacements costs are the sum of replacements costs of structures (line 35,36), equipment and software (line 4), and inventories (line 5). 


\subsection{Priors and Calibration}

We estimate several parameter for (i) the fiscal rule, (ii) the bubble process, (iii) the shock processes, and (iv) the Taylor-rule. All remaining parameters are calibrated to match quarterly data for the United States.

The discount factor $\beta$ is set to 0.99 , which equals an average real rate of $4 \%$ per year. Households preferences follow Bernanke et al. (1999) and the labor supply elasticity is set to 3. Further, the labor share, $\alpha$, is set to $2 / 3$, as discussed in King et al. (1988). The exogenous capital depreciation rate is set to 10 per cent per annum, which equals 0.025 per quarter. For the investment adjustment costs, we use the value proposed by Bernanke et al. (1999), namely 0.25, which is equal to the elasticity of the price of capital with regard to the investment capital ratio.

We assume that the average period between price changes is four quarters, setting the Calvo probability to 0.75 . The steady state of government spending is calibrated to equal 15 percent of output, close to the 0.2 reported in Bernanke et al. (1999).

The risk spread is set to two hundred basis points. This spread is close to the historically observed difference between the prime lending rate and the 6 month T-bill rate. In line with this spread, we calibrate the death rate of entrepreneurs to be 0.0272 . Further, this implies a business failure rate of three percent and a capital-to-net worth ratio of 2 . The leverage ratio is set to 0.5. Further, we need to calibrate idiosyncratic productivity and assume that it belongs to the lognormal family with variance 0.28 and the fraction of realized payoffs lost in bankruptcy is 0.12 .

We start with the prior choice for the fiscal rule parameters. We set the prior for the weight on debt, $\gamma_{\Xi}$, to follow a normal distribution with mean 0.25 and standard deviation 0.01. Similar, the prior for the weight on output, $\gamma_{Y}$, is normal around 0.25 with standard deviation 0.01 . Then, we choose a quite loose prior for the bubble process. It is assumed to be beta distributed around a mean of 0.7 and standard deviation 0.1 .

Furthermore, we estimate $\varphi$, which is the elasticity of the price with respect to the investment capital ratio. It is assumed to be beta distributed with mean 0.2 and standard deviation 0.05 .

Next, we set the priors related to our five exogenous processes: the autocorrelation parameters all follow beta distributions with mean 0.5 and standard deviation 0.2 . The mean of the standard deviations are set to 0.5 with standard deviation 0.2 , belonging to the inverse Gamma family.

Finally, we calibrate the monetary policy feedback parameters. The smoothing parameter, $\phi$, is beta distributed with mean 0.8 and standard deviation 0.1 . The weight on inflation, $\psi_{\pi}$, is normal with mean 1.5 and standard deviation 0.05 . The weight on output is assumed to be beta distributed with mean 0.125 and standard deviation 0.01 . Then, the third parameter in the Taylor rule is assumed to follow a normal distribution with mean 0.2 and standard deviation 0.2 , to allow for a quite wide prior.

\section{Discussion}

\subsection{Model Comparison}

In the following section we describe and conduct our model selection procedure. ${ }^{8}$ The distinct feature lies in the reaction function of the monetary authority. Specifically, we compare the standard monetary policy rule augmented by a reaction coefficient to emerging non-fundamental bubbles or other financial market variables, such as the fundamental capital price, the capital market price, the capital rental rate, the net worth, and investment. A key property is therefore that the central

\footnotetext{
${ }^{8}$ The appendix presents the mathematical representation of the Taylor rules for all the models considered.
} 
bank is able to identify bubble phenomena, which is a key issue in the "lean" vs. "clean" debate. In order to answer if the FED reacted to bubbles, we estimate our DSGE model along with the bubble process and alternative monetary policy rules. The minimum model log-likelihood selects the model with the best empirical fit.

Turning to Table 1, it is striking, that any kind of bubble-augmented monetary policy delivers an improved model fit. The standard model (see eq. (31)) performs worst. Then, the model including firm's net worth and Tobin's q perform second and third worst. There is no significant difference between the model with the model based Tobin's q and the model including the capital rental rate. The best empirical fit is obtained by a further reaction to investment or the nonfundamental bubble component. The difference in the likelihood is statistically insignificant. In any case, considering the correlation of the bubble and its symptoms with the classic conduct of monetary policy (Bernanke and Gertler (2000)), the gain in model goodness-of-fit, especially by the non-fundamental bubble component is remarkable. It is a strong indication of some kind of active monetary policy, surpassing the reaction to inflation and output. As both reactions, to investment and the non-fundamental bubble component, show similar model fits, we combine both policy functions, re-estimate our model, and look at the model coefficients in detail.

Table 1: Model comparison. $L L N$ is the log likelihood. Standard is the Taylor rule with output and inflation (see eq. (31)).

\begin{tabular}{|l|c|c|c|c|c|c|c|}
\hline Model & Standard & $\tilde{Q}$ & Capital Rental Rate & Net Worth & $Q$ & Investment & Bubble \\
\hline$L L N$ & -1707.68 & -1516.44 & -1489.02 & -1618.22 & -1493.81 & -1447.31 & -1454.69 \\
\hline
\end{tabular}

\subsection{Point Estimates}

For our estimation, we use two blocks of 250.000 draws each for our MCMC chains. Then, table 2 presents the posterior means of deep parameters and the $95 \%$ confidence interval. Column two and three report the estimates of the benchmark and augmented cases, respectively. At a first glance, it is noteworthy that all model parameters are significantly shifted away from their respective priors with small confidence bands, which implies that our data is informative. In both model versions, the central bank reacts strongly to inflation with a coefficient of roughly 1.4. Therefore, the central bank satisfies the Taylor principle. Nevertheless, there is a difference according to the reaction to output. Here a significant reaction can only be detected in the augmented framework. Our estimated extended Taylor rule reacts significantly to inflation (1.44), output (0.25), investment, $\psi_{I},(0.14)$, and the bubble, $\psi_{B},(0.89)$. The latter reaction to the bubble process comes close to unity and is therefore of substantial size. The reaction to investment includes a reaction of zero and therefore has to be treated with caution. Investment and output reaction could well be driven by correlation with the bubble symptom, while the sheer size of the reaction to inflation rules this being the only explanation out (in the sense of the "clean" proponents). In line with a reaction to bubbles, our estimated bubble coefficients are smaller if the FED reacts to them systematically. As our policy function is symmetric, we can say that the central bank reacted strongly to any kinds of asset price misalignment along with inflation targeting. As prior to the Great Recession there was a lack of bubble differentiation (Mishkin, 2011), we believe that our single bubble component along with its policy reaction models these circumstances closely. Moreover, throughout our sample period most of the bubble episodes can be defined as irrational exuberance, excluding the Great 


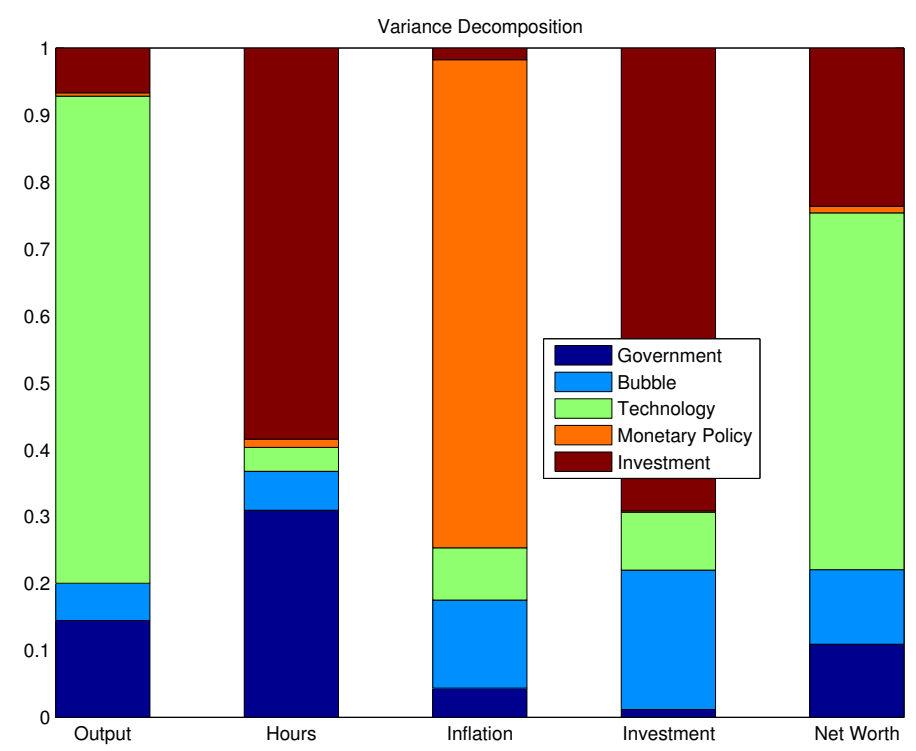

Figure 1: Variance decomposition for the standard model.

Recession. ${ }^{9}$ While our model does not allow for a channel from monetary policy to the bubble formation probability, the augmented model gives a lower persistence, $a$, of the bubble process compared to the standard model (0.82 vs. 0.93$)$. One can argue that a reaction to the asset price bubble lowers the duration of the bubble process. Therefore, the augmented monetary policy is able to reduce the relevance of bubbles compared to the standard monetary policy.

Turning to the remaining coefficients, the complementary fiscal policy adjusts to the more active monetary policy role. While the standard and augmented framework estimates put a higher weight on output than on debt, the absolute focus on output increases in the augmented model. Specifically, the augmented framework reacts to debt with a coefficient of 0.03 (Benchmark: 0.08) and to output with 0.37 (Benchmark: 0.15). All fiscal coefficients remain significantly positive. The remaining posterior means of the production function, shock sizes and persistence show only a few differences among the different setups. The estimated non-fundamental shock parameters shows a lower amplitude but higher persistence in the augmented model. The only shock with lower persistency is generally found for the monetary policy function. The hierarchy of estimated shocks according to size and persistence remains stable across the model alternatives.

\subsection{Variance Decomposition}

For a detailed analysis of both models we compare the explained unconditional variances. Figure 1 presents the variance decomposition for the standard model and figure 2 shows the variance decomposition for the full model (the model with a reaction to the bubble and investment).

In the benchmark model the three supply side shocks investment, technology, and the nonfundamental bubble process explain more than 80 percent of output variation. The remaining roughly 15 percent can be explained by government shocks. In the augmented monetary policy function setup investment shocks do not contribute to the output variation in the same manner. Further, while the impact of technology shocks decreases, this is compensated via increased contri-

\footnotetext{
${ }^{9}$ To underline this argumentation, we also run a robustness check on a subsample excluding the Great Recession. We do find a significant reaction to the bubble as well. The results are available upon request.
} 
Table 2: Posterior estimate for the standard, the augmented, and the asymmetric model.

\begin{tabular}{|c|c|c|c|}
\hline Parameter & Standard & Augmented & Asymmetric \\
\hline$\gamma_{\Xi}$ & $\begin{array}{c}0.08 \\
{[0.02,0.17]}\end{array}$ & $\begin{array}{c}0.03 \\
{[0.02,0.05]}\end{array}$ & $\begin{array}{c}0.05 \\
{[0.02,0.07]}\end{array}$ \\
\hline$\gamma_{Y}$ & $\begin{array}{c}0.15 \\
{[0.08,0.21]}\end{array}$ & $\begin{array}{c}0.37 \\
{[0.31,0.43]}\end{array}$ & $\begin{array}{c}0.32 \\
{[0.24,0.39]}\end{array}$ \\
\hline$\phi$ & $\begin{array}{c}0.50 \\
{[0.43,0.59]}\end{array}$ & $\begin{array}{c}0.78 \\
{[0.71,0.83]}\end{array}$ & $\begin{array}{c}0.54 \\
{[0.45,0.62]}\end{array}$ \\
\hline$\psi_{y}$ & $\begin{array}{c}0.01 \\
{[-0.05,0.05]}\end{array}$ & $\begin{array}{c}0.25 \\
{[0.20,0.29]}\end{array}$ & $\begin{array}{c}0.02 \\
{[-0.03,0.1]}\end{array}$ \\
\hline$\psi_{\pi}$ & $\begin{array}{c}1.37 \\
{[1.32,1.44]}\end{array}$ & $\begin{array}{c}1.44 \\
{[1.32,1.50]}\end{array}$ & $\begin{array}{c}1.5 \\
{[1.41,1.56]}\end{array}$ \\
\hline$\psi_{I}$ & - & $\begin{array}{c}0.14 \\
{[0.01,0.25]}\end{array}$ & $\begin{array}{c}0.3 \\
{[0.21,0.4]}\end{array}$ \\
\hline$\psi_{B}$ & - & $\begin{array}{c}0.89 \\
{[0.74,1.05]}\end{array}$ & $\begin{array}{c}0.6 \\
{[0.17,1.04]}\end{array}$ \\
\hline$\alpha$ & $\begin{array}{c}0.18 \\
{[0.14,0.22]}\end{array}$ & $\begin{array}{c}0.11 \\
{[0.09,0.13]}\end{array}$ & $\begin{array}{c}0.17 \\
{[0.13,0.21]}\end{array}$ \\
\hline$a$ & $\begin{array}{c}0.93 \\
{[0.93,0.93]}\end{array}$ & $\begin{array}{c}0.82 \\
{[0.60,0.93]}\end{array}$ & $\begin{array}{c}0.93 \\
{[0.93,0.93]}\end{array}$ \\
\hline$\rho_{B}$ & $\begin{array}{c}0.59 \\
{[0.55,0.63]}\end{array}$ & $\begin{array}{c}0.75 \\
{[0.60,0.95]}\end{array}$ & $\begin{array}{c}0.99 \\
{[0.99,0.99]}\end{array}$ \\
\hline$\overline{\rho_{Z}}$ & $\begin{array}{c}0.99 \\
{[0.99,0.99]}\end{array}$ & $\begin{array}{c}0.99 \\
{[0.99,0.99]}\end{array}$ & $\begin{array}{c}0.99 \\
{[0.99,0.99]}\end{array}$ \\
\hline$\rho_{S}$ & $\begin{array}{c}0.99 \\
{[0.99,0.99]}\end{array}$ & $\begin{array}{c}0.99 \\
{[0.99,0.99]}\end{array}$ & $\begin{array}{c}0.99 \\
{[0.99,0.99]}\end{array}$ \\
\hline$\overline{\rho_{G}}$ & $\begin{array}{c}0.99 \\
{[0.99,0.99]}\end{array}$ & $\begin{array}{c}0.99 \\
{[0.99,0.99]}\end{array}$ & $\begin{array}{c}0.99 \\
{[0.99,0.99]}\end{array}$ \\
\hline$\rho_{R}$ & $\begin{array}{c}0.27 \\
{[0.18,0.36]}\end{array}$ & $\begin{array}{c}0.17 \\
{[0.07,0.26]}\end{array}$ & $\begin{array}{c}0.02 \\
{[0.002,0.03]}\end{array}$ \\
\hline$\sigma_{B}$ & $\begin{array}{c}1.73 \\
{[1.55, .190]}\end{array}$ & $\begin{array}{c}1.49 \\
{[1.36,1.61]}\end{array}$ & $\begin{array}{c}0.12 \\
{[0.11,0.14]}\end{array}$ \\
\hline$\overline{\sigma_{Z}}$ & $\begin{array}{c}0.71 \\
{[0.66,0.76]}\end{array}$ & $\begin{array}{c}0.71 \\
{[0.65,0.76]}\end{array}$ & $\begin{array}{c}0.72 \\
{[0.66,0.78]}\end{array}$ \\
\hline$\sigma_{S}$ & $\begin{array}{c}2.51 \\
{[2.27,2.75]}\end{array}$ & $\begin{array}{c}2.23 \\
{[2.04,2.44]}\end{array}$ & $\begin{array}{c}2.97 \\
{[2.7,3.23]}\end{array}$ \\
\hline$\sigma_{G}$ & $\begin{array}{c}5.53 \\
{[4.96,6.10]}\end{array}$ & $\begin{array}{c}5.32 \\
{[4.88,5.73]}\end{array}$ & $\begin{array}{c}5.57 \\
{[5.05,6.1]}\end{array}$ \\
\hline$\sigma_{R}$ & $\begin{array}{c}0.51 \\
{[0.45,0.56]}\end{array}$ & $\begin{array}{c}0.50 \\
{[0.43,0.57]}\end{array}$ & $\begin{array}{c}1.78 \\
{[1.58,1.98]}\end{array}$ \\
\hline
\end{tabular}

butions of the bubble and government spending shock. Especially, the latter component increases from explaining roughly 12 to almost 50 percent of output variation. Working hours show a similar pattern. While investment shocks and to a lower extent government consumption shocks contribute to over ninety percent of the variation in the benchmark model, shocks to government spending, and the non-fundamental bubble feed into this variation in the alternative setup. Turning to inflation, monetary policy explain a major share (70 percent) of fluctuations in the standard model. However, in the augmented model, the contribution of monetary policy is almost entirely replaced by shocks to investment, technology, government consumption and the capital market pricing equation. This observation can be explained by replacing the former variation accounted for by a monetary policy shock by an extended structural response to investment and the bubble phenomenon. Also in the remaining variables, monetary policy shocks do not play a major share in explaining key model dynamics. Investment dynamics can be decomposed into investment shocks (over 60 percent) in both model setups. Most of the remaining variation seems to be driven by the non-fundamental 


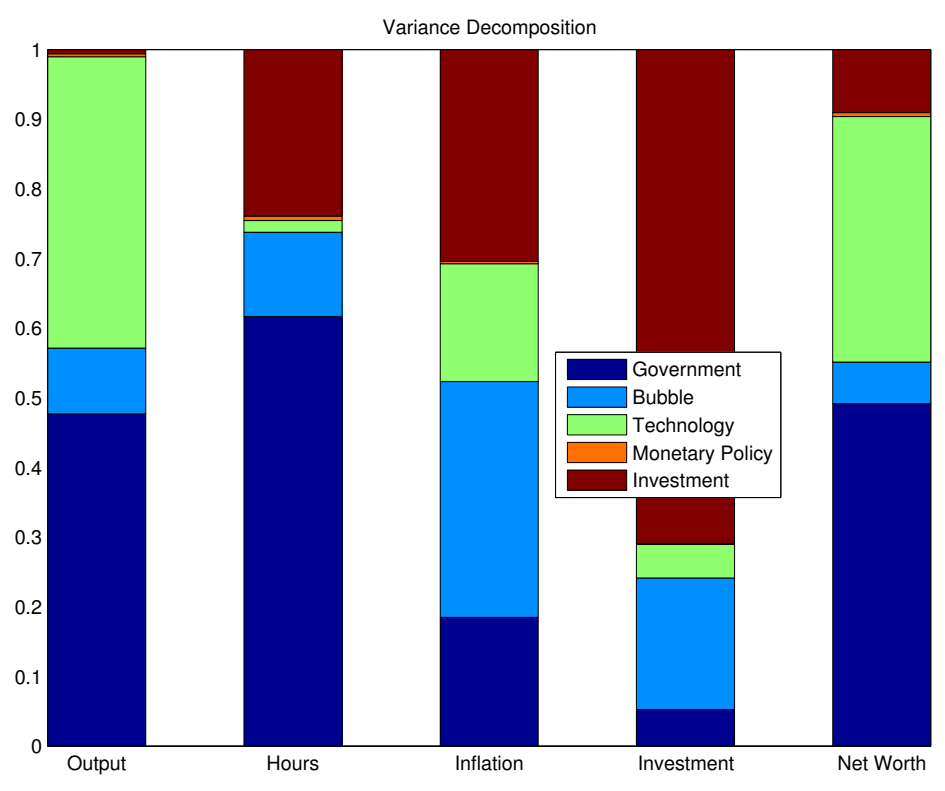

Figure 2: Variance decomposition for the full model.

bubble shock. Opposed to the other variables, the drivers of investment changes are unaffected by the choice of monetary policy reaction. Finally, in the baseline scenario, net worth variation can be decomposed into two main shocks, i.e. investment and technology (roughly 80 and 40 percent in the respective model setups). While the non-fundamental bubble shock explains a fairly large share in both setups, especially the government shock accounts for half of the augmented model dynamics. Overall, it can be summarized that shocks to government consumption, technology, and the non-fundamental bubble process explain most of the variation in the augmented setup, whereas shocks to investment, technology shocks and again the bubble contribute most to the benchmark case dynamics. Therefore, the bubble process is meaningful in both model setups.

\subsection{Counterfactual Analysis}

In this section we present a counterfactual analysis for different Taylor rules. Figure 3 presents time series for output, the interest rate, and investment for three different cases from 1952 to 2012. First, the standard Taylor rule without bubble and investment. Second, the Taylor rule with bubble and investment term, and, third, the augmented rule but estimated with the shocks from the model without these additional terms.

In general, we find that the interest rate is larger in the augmented Taylor rule model than in the standard Taylor rule model and much closer to the data (not shown here). The exception is the time span from 1972 to 1987. In those 15 years, the standard Taylor rule model generated a larger interest rate. In the New Keynesian model, higher interest rates reduce incentives to consume today and shift consumption to the future. As a consequence, private agents spend less and save more. Hence, investment is larger in the model with the augmented Taylor rule than in the model with the standard Taylor rule. The negative effect of higher interest rates is not compensated by larger investment and, therefore, output is lower in the model with the augmented Taylor rule.

Before the Great Recession, we find that the interest rate is larger in the augmented model than in the standard model. During the period from 2002 to 2007 we find that the increase in output 

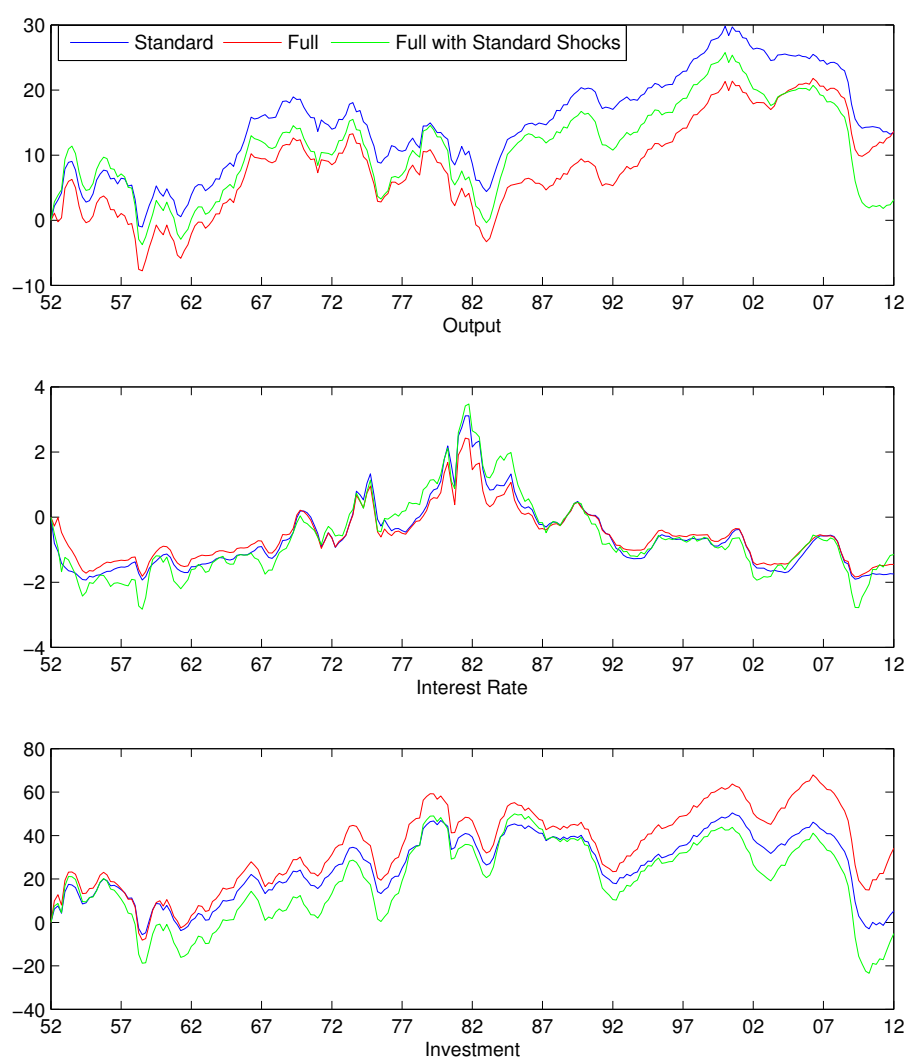

Figure 3: Counterfactual analysis. Simulation from 1952 to 2012.

is larger in the augmented model than in the standard model. This is mainly driven by a strong increase in investments. The effect of the shock(s) on output and investment are similar across models. However, we find that the recovery in the augmented model happens much faster than in the standard model. In fact, while output is still decreasing at the end of our sample, it starts to increase right after the drop around 2008.

It should be stressed that the difference between the standard and the full model can not be traced back to differences in the estimated shocks. The simulation with the full model and the standard shocks proofs that there is a systematic difference - in monetary policy - between the two simulations.

We can draw the conclusion that the FED reacted to movements in asset prices while this resulted in a lower level of output throughout our simulation period. Nevertheless, the drop caused by the financial crisis is smaller in the simulation with a reaction which implies that the FED is successful in reducing the adverse effects of a bursting bubble.

\subsection{Asymmetric Taylor Rule}

So far our results are based upon a key assumption: symmetry. Positive and negative deviations of the asset price from its fundamental value (the value of Tobin's q generated by the model) have 
been treated equally. One might argue that the FED should be more concerned with positive than negative deviations. In order to study the effects of an asymmetric response to bubbles, we estimate a version of the model where the FED only reacts to positive deviations of asset prices. The Taylor rule can then be written as

$$
R_{t}=\phi R_{t-1}+(1-\phi)\left[\psi_{y} Y_{t}+\psi_{\pi} \pi_{t}+\psi_{I} I_{t}+\mathbf{1}_{B} \psi_{B} \psi_{t}\right]+u_{t}^{R}
$$

where $\mathbf{1}_{B}$ is an indicator function that is 1 if $\psi_{t}>0$ and 0 otherwise.

Table 2 presents the estimated parameters for the asymmetric Taylor rule specification. We find a smaller reaction to the asset price bubbles compared to the symmetric case (0.6 vs. 0.84 ). This implies a smaller reaction if we only focus on positive asset price deviations. This also reduces the problem of misinterpreting asset price movements that do not cause a bubble. Further, we now observe a positive and significant reaction to investment in the Taylor rule. The reaction is half as strong compared to the bubble. We can interpret this significant coefficient as a cleaning component of monetary policy as it would counteract the adverse effects of a bursting bubble on investment and, therefore, real activity.

Figure 4 shows the simulation of the model with the symmetric (red line) and the asymmetric (blue line) monetary policy response to the asset price bubble. We find that the asymmetric rule is much closer to the standard model and the data compared to the symmetric model (log-likelihood is -1435.71). This holds until 1992, when the simulated time series for output and investment are larger in the symmetric case. The drop due to the financial crisis is of similar size in both versions. However, in the symmetric case we observe a slight increase, i.e. a recovery, after the sharp decline in real activity. In contrast, we observe a negative trend in output for the asymmetric version.

We can draw the conclusion that the asymmetric rule is a more realistic description of monetary policy in the United States. The generated time series are close to the data and outperform the standard model. This holds until 1992, when both versions perform bad. Again, we find that the drop associated with the financial crisis is smaller compared to the standard model. In addition, we observe that the symmetric model generates a recovery not present in the asymmetric or the standard model.

\section{Conclusion}

Recent financial market turmoils in the United States (housing bubble and the collapse of Lehman Brothers) and Europe (sovereign debt crisis) have shown that disturbances in the financial system can have substantial and persistent real effects. Therefore, the interest of academia in the proper functioning of financial markets and the implications of shocks in the financial system for the economy has increased.

In particular, the recent past has reinforced the viewpoint that monetary policy should react to non-fundamental deviations of asset prices (see, for example, Mishkin (2011)). This debate is known as the "lean" versus "clean" debate. Should the central bank react to asset price movements or should she try to limit the effects of bursting bubbles? While the normative literature on this issue is quite large, the empirical literature is rather sparse. We're focusing on the latter and abstract from the normative dimension of this debate. Our contribution is purely empirical and sheds light on the behavior of the Federal Reserve bank with regard to asset price bubbles.

We develop a New Keynesian model of the U. S. business cycle. Our model features financial frictions in the spirit of Bernanke et al. (1999). Further, we augment this model by adding a fiscal policy rule with endogenous feedback to output and sovereign debt and add a process that accounts for non-fundamental deviations in asset prices, i.e. a bubble. Then, we estimate this model using 

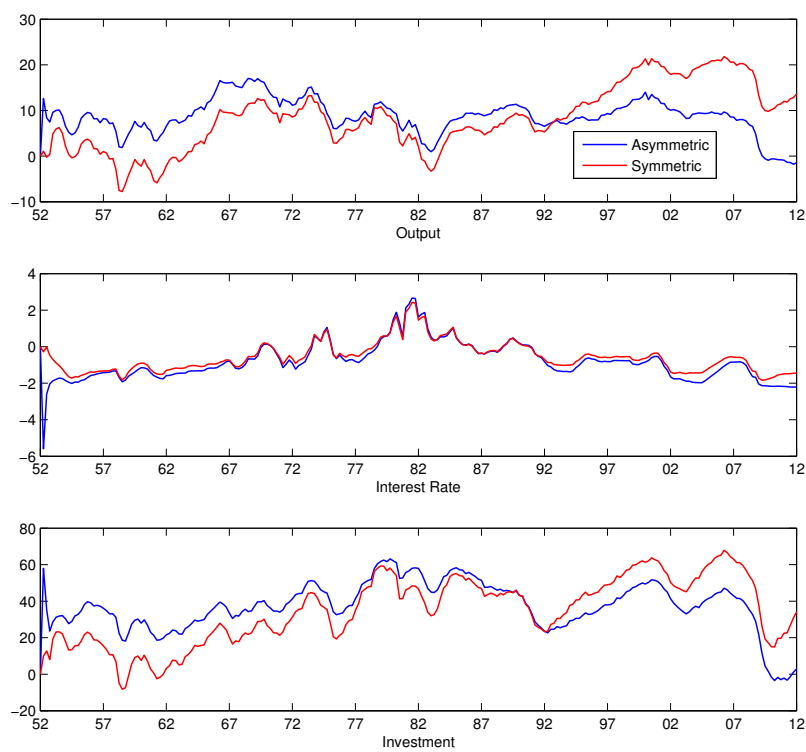

Figure 4: Simulation for the asymmetric vs. symmetric policy response.

Bayesian methods on quarterly macroeconomic time series over the sample from 1960 to 2012 for the United States.

Several findings stand out. First, we show that the inclusion of bubbles improves the model fit. The estimated reaction coefficient to the non-fundamental component is close to unity. Together with the strong inflation targeting this result indicates an active response to bubbles. Second, we perform a counterfactual analysis, comparing a model with a reaction to the asset price bubble in the Taylor rule with a model without a reaction. We find that the output level is lower if the central banks reacts to the asset price bubble. Finally, we estimate an asymmetric version and find that it only marginally increases the fit to the data. It does generate a better fit compared to the symmetric rule before 1992 but a worse fit afterwards. In summation, the FED reacts to asset price bubbles at the cost of a lower output level. Including the bubble reduces the negative effects of the recent financial crisis but the symmetric response would have generated an earlier and stronger recovery. One limiting factor of our analysis is the absence of a transmission channel from monetary policy to the probability of future asset price bubbles. Future research will take this channel into account.

Finally, we want to stress some policy implications. Trivially, private investors want to operate under perfect information. A central bank clearly reacting to asset price deviations (potential bubbles) increases transparency about the bank's policy; eliminating the discussion whether the FED prefers "lean" or "clean". Further, it makes sure that market participants understand that the central bank will lean against bubbles as the costs of cleaning are too high and adverse effects towards the real economy are potentially large. This could reduce the probability of a bubble formation and limit the effects on the real economy. If monetary policy is able to reduce the likelihood of bubbles, they should be able to drive down risk in the asset market as the fundamental value of the asset becomes more important. 
Moreover, as the central bank in our model is able to clearly identify bubbles from the moment they start, the central bank is able to pick the bubble at an early stage and limit its effects on the market. 


\section{Appendix}

- Standard

$$
R_{t}=\phi R_{t-1}+(1-\phi)\left[\psi_{y} Y_{t}+\psi_{\pi} \pi_{t}\right]+u_{t}^{R}
$$

- $\tilde{Q}$

In this version, we augment the standard model by adding the observed Tobin's q to the Taylor rule

$$
R_{t}=\phi R_{t-1}+(1-\phi)\left[\psi_{y} Y_{t}+\psi_{\pi} \pi_{t}+\psi_{Q t} \tilde{Q}_{t}\right]+u_{t}^{R}
$$

Obviously, the asset price bubble will have an affect on Tobin's q.

- Capital Rental Rate

The third version includes the capital rental rate

$$
R_{t}=\phi R_{t-1}+(1-\phi)\left[\psi_{y} Y_{t}+\psi_{\pi} \pi_{t}+\psi_{R} R_{t}^{k}\right]+u_{t}^{R},
$$

as there is a link between the asset prices and the price of renting capital from households.

- Net Worth

The next version includes the firm's net worth

$$
R_{t}=\phi R_{t-1}+(1-\phi)\left[\psi_{y} Y_{t}+\psi_{\pi} \pi_{t}+\psi_{N} N_{t}\right]+u_{t}^{R},
$$

because the price and the quantity of capital directly affects the net worth of our representative firm. Further, because net worth is a constraint on borrowing, the central bank should have an interest in this variable as a proxy for the maximum lending.

- $Q$

Here, we add Tobin's q computed from the DSGE model (the fundamental $Q$ )

$$
R_{t}=\phi R_{t-1}+(1-\phi)\left[\psi_{y} Y_{t}+\psi_{\pi} \pi_{t}+\psi_{Q} Q_{t}\right]+u_{t}^{R},
$$

as the central banks should be interested in the fundamental value of asset prices.

- Investment

$$
R_{t}=\phi R_{t-1}+(1-\phi)\left[\psi_{y} Y_{t}+\psi_{\pi} \pi_{t}+\psi_{I} I_{t}\right]+u_{t}^{R}
$$

The asset price bubbles directly affects the costs of investment and we therefore expect the central bank to monitor the movements in investment carefully.

- Bubble

$$
R_{t}=\phi R_{t-1}+(1-\phi)\left[\psi_{y} Y_{t}+\psi_{\pi} \pi_{t}+\psi_{B} \psi_{t}\right]+u_{t}^{R} .
$$

Naturally, the inclusion of the bubble should perform best as it enables the central bank to identify non-fundamental deviations. 


\section{References}

[1] Bean, C., 2004. Asset Prices, Financial Instability, and Monetary Policy..American Economic Review, Papers and Proceedings, 94(2): 14-18.

[2] Bekaert, G., M. Hoerova and M. Lo Duca, 2013. Risk, Uncertainty and Monetary Policy. Journal of Monetary Economics, 60(7): 771-788.

[3] Bernanke, B., M. Gertler, and S. Gilchrist, 1999. The Financial Accelerator in a Quantitative Business Cycle Framework. Handbook of Macroeconomics, 1(1): 1341-1393.

[4] Bernanke, B. and M. Gertler, 2001. Should Central Banks Respond to Movements in Asset Prices? American Economic Review, Papers and Proceedings, 91(2): 253-257.

[5] Bernanke, B. and M. Gertler, 2000. Monetary Policy and Asset Price Volatility. NBER Working Paper, No. 7559.

[6] Bjornland, C. and K. Leitemo, 2009. Identifying the Interdependence between U. S. Monetary Policy and the Stock Markt. Journal of Monetary Economics, 56(2): 275-282.

[7] Bordo, M. and O. Jeanne, 2002. Monetary Policy and Asset Prices: Does "Benign Neglect" Make Sense? International Finance, 5(2): 139-164.

[8] Calvo, G., 1983. Staggered Prices in a Utility-Maximizing Framework. Journal of Monetary Economics, 12: 383-398.

[9] Carlstrom, C. and T. Fuerst, 2007. Asset Prices, Nominal Rigidies, and Monetary Policy. Review of Economic Dynamics, 10(2): 256-275.

[10] Cecchetti, S., H. Genberg, J. Lipsky, and S. Wadhwani, 2000. Asset Prices and Central Bank Policy. Geneva Reports on the World Economy No. 2.

[11] Cecchetti, S., H. Genberg, and S. Wadhwani, 2002. Asset Prices in a Flexible Inflation Targeting Framework. NBER Working Papers 8970.

[12] Christiano, L., M. Eichenbaum, and C. Evans, 2005. Nominal Rigidities and the Dynamic Effects of a Shock to Monetary Policy. Journal of Political Economy, 113(1): 1-45.

[13] Christiano, L., R. Motto, and M. Rostagno, 2010. Financial Factors in Economic Fluctuations. Mimeo.

[14] Detken, C. and F. Smets, 2004. Asset Price Booms and Monetary Policy. ECB Working Paper, No. 364

[15] Dupor, B., 2001. Nominal Prices Versus Asset Price Stabilization. University of Pennsylvania Working Paper,.

[16] Dupor, B., 2005. Stabilizing Non-Fundamental Asset Price Movements Under Discretion and Limited Information. Journal of Monetary Economics, 52(4): 727-747.

[17] Dupor, B. and T. Conley, 2004. The Fed Response to Equity Prices and Inflation. American Economic Review, Papers and Proceedings, 94(2): 24-28. 
[18] Faia, E. and T. Monacelli, 2007. Optimal Interest Rate Rules, Asset Prices, and Credit Frictions. Journal of Economic Dynamics and control, 31(10): 3228-3254.

[19] Farhi, E. and J. Tirole, 2012. Collective Moral Hazard, Maturity Mismatch, and Systemic Bailouts. American Economic Review, 102(1): 60-93.

[20] Filardo, A., 2001. Should Monetary Policy Respond to Asset Price Bubbles? Some Experimental Results. Federal Reserve Bank of Kansas Working Paper, No. 01-04.

[21] Filardo, A., 2004. Monetary Policy and Asset Price Bubbles: Calibrating the Monetary Policy Trade-Offs. BIS Working Papers, No. 155.

[22] Forni, L., L. Monteforte, and L. Sessa, 2009. The General Equilibrium Effects of Fiscal Policy: Estimates for the Euro Area. Journal of Public Economics, 93(3-4): 559-585.

[23] Fuhrer, J. and G. Tootell, 2008. Eyes on the Prize: How Did the Fed Respond to the Stock Markt? Journal of Monetary Economics, 55(4): 796-805.

[24] Gilchrist, S. and M. Saito, 2008. Expectations, Asset Prices, and Monetary Policy: The Role of Learning. NBER Chapters, in: Asset Prices and Monetary Policy: 45-102.

[25] Gilchrist, S. and J. Leahy, 2002. Monetary Policy and Asset Prices.

[26] Hall, P., 2011. Is There Any Evidence Of a Greenspan Put? Swiss National Bank Working Paper, 2011-6.

[27] Hoffmann, A., 2013. Did the Fed and ECB React Asymmetrically With Respect To Asset Market Developments. Journal of Policy Modelling, 35(2): 197-211.

[28] Ikeda, D., 2013. Monetary Policy and Inflation Dynamics in Asset Price Bubbles. Bank of Japan.

[29] In't Veld, J., R. Raciborski, M. Ratto, and W. Roeger, 2011. The Recent Boom-bust Cycle: The Relative Contribution of Capital Flows, Credit Supply, and Asset Bubbles. European Economic Review, 55(3): 386-406.

[30] Issing, O., 2011. Lessons for Monetary Policy: What Should the Consensus Be? IMF Working Paper 11/97.

[31] King, R., C. Plosser, and S. Rebelo, 1988. Production, Growth and Business Cycles: The Basic Neoclassical Model. Journal of Monetary Economics, 21(2-3): 195-232.

[32] Leeper, E., 1991. Equilibria under 'Active' and 'Passive' Monetary and Fiscal Policies. Journal of Monetary Economics, 27(1): 129-147.

[33] Liu, Z., P. Wang, and T. Zha, 2013. Land-Price Dynamics and Macroeconomic Fluctuations, Econometrica, May: 1147-1184.

[34] Luik, M. A. and D. Wesselbaum, 2014. Bubbles Over the Business Cycle: A Macroeconometric Approach. Journal of Macroeconomics, 40(June 2014): 27-41.

[35] Miao, J., P. Wang, and Z. Xu, 2012. A Bayesian DSGE Model of Stock Market Bubbles and Business Cycles. Boston University Working Paper,. 
[36] Mishkin, F., 2011. Monetary Policy Strategy: Lessons From the Crisis. NBER Working Papers 16755 .

[37] Ratto, M., W. Roeger, and J. in't Veld, 2010. Using a DSGE Model to look at the Recent Moom-bust Cycle in the U. S.. European Commission, Economic Papers 397.

[38] Ravn, S., 2014. Asymmetric Monetary Policy Towards the Stock Market: A DSGE approach. Journal of Macroeconomics, 39(A): 24-41.

[39] Ravn, S., 2012. Has the Fed Reacted Asymmetrically to Stock Prices. The B.E. Journal of Macroeconomics, 12(1): 1-36.

[40] Rigobon, R. and B. Sack, 2004. The Impact of Monetary Policy on Asset Prices. Journal of Monetary Economics, 51(8): 1553-1575.

[41] Smets, F. and R. Wouters, 2007. Shocks and Frictions in U. S. Business Cycles: A Bayesian DSGE Approach. American Economic Review, 97(3): 586-606.

[42] Tetlow, R., 2005. Monetary Policy, Asset Prices and Misspecification: The Robust Approach to Bubbles with Model Uncertainty. Mimeo.

[43] Townsend, R., 1979. Optimal Contracts and Competitive Markets with Costly State Verification. Journal of Economic Theory, 21: 265-293.

[44] Wang, P. and Y. Wen, 2012. Speculative Bubbles and Financial Crises. American Economic Journal: Macroeconomics, 4(3): 184-221.

[45] White, W., 2009. Should Monetary Policy "'Lean or Clean"'?. Federal Reserve Bank of Dallas Globalization and Monetary Policy Institute Working Paper No. 34. 